\title{
Integration of stabilized bio-oil in light cycle oil hydrotreatment unit targeting hybrid fuels
}

\author{
Athanasios Dimitriadis ${ }^{\mathrm{a}}$, George Meletidis ${ }^{\mathrm{a}}$, Ulrich Pfisterer ${ }^{\mathrm{b}}$, Miloš Auersvald ${ }^{\mathrm{c}}$, \\ David Kubička ${ }^{c}$, Stella Bezergianni ${ }^{\text {a, * }}$ \\ ${ }^{a}$ Laboratory of Environmental Fuels and Hydrocarbons - LEFH, Chemical Process \& Energy Resources Institute - CPERI, Centre for Research and Technology Hellas - \\ CERTH, 6km Harilaou-Thermi, Thessaloniki, Greece \\ b BP Europa SE, Bochum, Germany \\ ${ }^{\mathrm{c}}$ University of Chemistry and Technology Prague, Department of Petroleum Technology and Alternative Fuels, Technická 5, 16628 Prague, Czech Republic
}

\section{A R T I C L E I N F O}

\section{Keywords:}

Co-hydroprocessing

Hydrodeoxygenation

Bio-oil

Catalytic pyrolysis oil

Hybrid fuel

Biofuel

\begin{abstract}
A B S T R A C T
Fast pyrolysis bio-oil requires upgrading in order to be used as an intermediate refinery stream as it contains various acids, oxygenates, heavy compounds and water. This work examines the potential of integrating the organic phase (called BioMates) of a hydrotreated pyrolysis bio-oil as a reliable intermediate refinery stream to be co-processed with a light cycle oil (LCO) towards the production of hybrid fuels. Three blends of BioMates with LCO were fed in a hydroprocessing pilot plant (10/90, 20/80 and 30/70 v/v BioMates/LCO). The dedicated tests aimed to study the BioMates effect on the LCO hydrodesulphurization performance, hydrogen consumption, product quality and catalyst life. The results have confirmed that over $85 \%$ per weight of the final product is between 60 and $360{ }^{\circ} \mathrm{C}$ boiling range and exhibit favorable fuel properties. The technology can process up to $30 \%$ per volume BioMates in LCO without any significant technical limitation, while reducing the hydrogen consumption up to $8.9 \%$. Finally, based on the findings, no clogging or permanent loss of catalyst effectiveness was observed after 37 days on stream.
\end{abstract}

\section{Introduction}

Biomass integration in an existing petroleum refinery exhibits a growing interest due to the environmental concerns and increasing energy demands. The utilization of petroleum refineries' underlying conversion capacity via well-established technologies capable to process alternative feeds with low investments costs, is particularly advantageous. Specifically, co-hydroprocessing is attracting much attention from technical and environmental point of view as an appropriate process to upgrade low quality refinery streams with biomass (e.g., high polyaromatic and/or sulphur contents) [1-3].

The last years, a very promising bio-based feed is fast pyrolysis biooil as it is produced from non-food origin. However, fast pyrolysis bio-oil consists of various oxygenated compounds as well as water and as a result it is unstable during storage. [4]. Thus, direct blends of pyrolysis bio-oil with petroleum streams are avoided due to its complex composition. To that aim, fast pyrolysis bio-oil has to be upgraded to a less oxygenated product in order to be blended with petroleum fractions [5].

Catalytic hydrotreatment is a proven technology for heteroatoms $(\mathrm{N}$, $\mathrm{S}, \mathrm{O}$ and metals) removal and saturation. As a result, hydrotreating is considered a promising technology for fast pyrolysis bio-oil stabilization, targeting to bio-oil conversion to conventional hydrocarbon fuels by removing the oxygenated compounds and reducing its polarity [6]. In fact, it has been experimentally proven that the challenging low quality of pyrolysis bio-oil can be improved via a single hydrotreating step resulting in a more stable product with higher energy density than the pure fast pyrolysis bio-oil [7,8].

In general, hydrotreatment of bio-oil involves the contact of bio-oil

Abbreviations: AFP, Ablative Fast Pyrolysis; CERTH, Centre for Research \& Technology Hellas; CPERI, Chemical Process \& Energy Resources Institute; DOS, Days

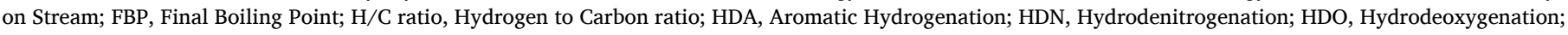

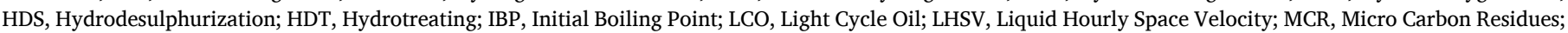

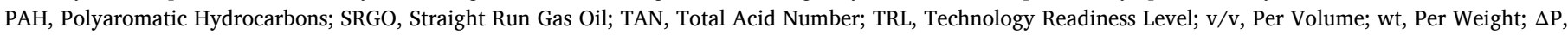
Pressure difference.

* Corresponding author.

E-mail address: sbezerg@cperi.certh.gr (S. Bezergianni). 
molecules with hydrogen under pressure between 70 and 90 bar and temperature $(<673 \mathrm{~K})$ over fixed bed catalytic reactors. Pyrolysis bio-oil can be fully deoxygenated via hydrodeoxygenation and decarboxylation reactions leading to a two-phase liquid product consisting of an organic (up to $60 \%$ per volume) and an aqueous phase (up to $40 \%$ per volume) [9]. Furthermore, off-gas containing light hydrocarbons, excess hydrogen and carbon dioxide is also produced as a by-product. After the stabilization step, the organic phase can be processed into conventional fuels or can be used as a blending component in a refinery for coprocessing with petroleum streams [10]. It should be noted that the severity of stabilization process (temperature, pressure) defines the rate of pyrolysis oil upgrading. Thus, more severe conditions characterized by higher operation costs. As a result, co-processing of a partially stabilized pyrolysis oil with petroleum stream into the existing petroleum refining infrastructure can reduce the capital cost instead of constructing new parallel infrastructure for standalone pyrolysis oil hydroprocessing to final fuel blend. In addition, there are some refinery streams such as LCO (light cycle oi) that are of such low quality that their individual upgrading to fuel is not profitable. In that case, co-processing of these refinery streams with bio-based feeds may better justify their upgrading. For that reasons, co-processing of partially stabilized pyrolysis oil with low quality petroleum streams is an attractive option for the production of hybrid biofuels that fulfill the requirements of the relevant directives of the European Union for biofuels.

Up to now, the literature on co-hydroprocessing of bio-oil with petroleum-based fractions is rather limited [11], while most of the studies examine model compounds such as guaiacol with straight run gas oil (SRGO) to simulate the effect of a bio-oil in an existing petroleum refinery [12-16]. Co-hydrotreatment of a hardwood-origin pyrolysis bio-oil was investigated by Pinheiro et al. [11], studying the effect of integrated bio-oil on hydrodesulphurization (HDS), hydrodenitrogenation (HDN) and aromatic hydrogenation (HDA) reactions during co-hydrotreatment with SRGO. It was found that, the HDS, HDN and HDA reactions are inhibited with the addition of bio-oil, due to the presence of $\mathrm{CO}$ and $\mathrm{CO}_{2}$ formed during the reaction [11]. Furthermore, co-hydrocracking of fast pyrolysis oil with vacuum gas oil and vacuum residue in both continuous process and batch or semi-batch processes was investigated by the group of Bergvall et al. [15]. Their results have indicated that the continuous process is preferred from coke and gas yield viewpoint. At the next phase, the same group in another study, has investigated the co-refined of fast pyrolysis oil with vacuum gas oil in an absence of very heavy vacuum residue that allowed the use of milder process conditions [16]. According to theirs results, continuous slurry hydrocracking of fast pyrolysis oil with vacuum gas oil appears to be a promising technology for the conversion of fast pyrolysis oil to intermediate transportation fuel.

Furthermore, various commercial hydrotreating catalysts have been also investigated with model compounds [12-14,17-19]. Typical oxygenates, such as propionic acid and ethyl decanoate, 2-propanol, anisole, cyclopentanone, guaiacol that exists in bio-oil can be fully deoxygenated at standard operating conditions (i.e., at $>603 \mathrm{~K},>3 \mathrm{MPa}$ and $1 \mathrm{~h}^{-1}$ ) when co-processed in blends with SRGO under commercial catalyst [12]. According to the literature findings, water is the only product of deoxygenation while there is no inhibition effect between the deoxygenation reactions and HDS, HDN and HDA. However, it was found that ethyl decanoate and propionic acid cause a strong inhibition on the HDS, HDN and HDA reactions which is a result of the deoxygenation by-products $\left(\mathrm{CO}\right.$ and $\left.\mathrm{CO}_{2}\right)$ [12,14]. Finally, Mercader et al. [13] have noticed that there is no catalyst permanent deactivation from the competition between the HDS and HDO reactions. All these studies examined the co-processing of bio-oil with petroleum-based feeds, however, there are no studies in the field of co-processing of upgraded/ stabilized bio-oil with fossil counterparts.

In our previous work an ablative fast pyrolysis was partially upgraded via hydrotreatment to a liquid product with low oxygen and water content [20]. The resulting product, called BioMates, was a potential intermediate refinery feedstock. The aim of this work is to show the extent of the co-processing potential. LCO was selected as appropriate petroleum feed candidate for co-hydroprocessing with the BioMates, based on an author's previous work focusing on the miscibility of BioMates with several refinery intermediates and the compatibility with their fuel characteristics [21,22]. According to this study, the binary blend of the BioMates and LCO showed increased homogeneity, while fuel characteristics such as density, viscosity, elemental composition, refractive index and boiling point distribution exhibited certain similarity. In this study, a deep investigation was carried out studying the effect of BioMates on catalyst life expectancy, hydrogen consumption and product quality during its co-hydroprocessing with LCO in various blending ratios. The experiments were conducted in a continuous flow, hydroprocessing pilot plant of Centre for Research and Technology Hellas (CERTH) in Greece. The current approach provides a profound insight into the integration of BioMates in an existing LCO hydrotreatment refinery unit for future research on potential production of hybrid fuels.

\section{Methodology}

The current investigation is a part of a European Union's Horizon 2020 research and innovation program under the grant agreement No 727463 with the project name "BioMates" [10]. In the first part of the project, the upgrading of fast pyrolysis bio-oil via hydrotreatment was investigated [20]. Within the current research, the potential of the upgraded bio-oil (BioMates) as a suitable intermediate feed for coprocessing with a petroleum fraction in a typical refinery for hybrid fuel production was examined. More specifically, three blends of light cycle oil (LCO) and BioMates were investigated in a fixed bed pilot hydrotreating plant during co-hydroprocessing via continuous flow.

\subsection{Feed and catalyst}

The pure bio-oil was produced by Fraunhofer UMSICHT [23,24] via an ablative fast pyrolysis (AFP) with staged condensation of a mixture made from barley and wheat straw at $50 \mathrm{wt} \%$ each, supplied by the company Erhard Meyer. The obtained bio-oil was further upgraded via hydrotreatment [20] (HDT) at the Center for Research and Technology Hellas (CERTH) in a pilot hydroprocessing plant as a first part of the BioMates research project [10]. The HDT of AFP bio-oil product is a twophase liquid consisting of an organic fraction $(60-70 \% v / v)$ and a nonmiscible aqueous fraction $(30-40 \% \mathrm{v} / \mathrm{v})$, as depicted in Picture $1 \mathrm{~B}$. The aqueous phase product was removed via descending, while the organic product was used as the main bio-based (BioMates) feed for the coprocessing tests. The results of the first part of the project for the hydrotreatment upgrading of the pure bio-oil were published in an author's previous research and thus no further details are presented in the manuscript [20].

The BioMates phase of HDT bio-oil was blended at three blending ratios $(10 \%, 20 \%$ and $30 \%$ per volume BioMates) with LCO that was provided from a BP refinery, none of which contained any additives. LCO was selected via a detailed preceding study [21,23], as the most compatible candidate from a miscibility perspective for co-processing with BioMates, as it consists of more polar molecules like aromatics, similarly to BioMates, therefore sharing similar challenges as a feedstock for hybrid fuel production and also presented very good miscibility with the BioMates. The addition even of $10 \%$ per volume BioMates in neat LCO has caused a color change of the sample, as BioMates is darker than LCO (Picture 2). The colors of the samples of 20/80 and 30/70 BioMates/LCO blends were similar and for brevity reasons they are not presented. The properties of pure bio-oil, BioMates, LCO as well as of the three BioMates/LCO blends are presented in Table 1.

The density of AFP bio-oil is higher compared to the maximum diesel specification $(0.820-0.845 \mathrm{~g} / \mathrm{mL})$. In addition, it is characterized by high oxygen content and total acid value (TAN), while it consists of less 


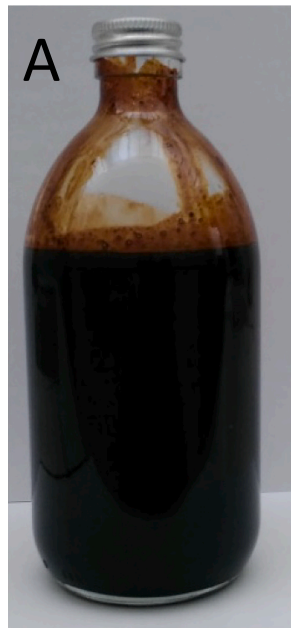

Bio-oil

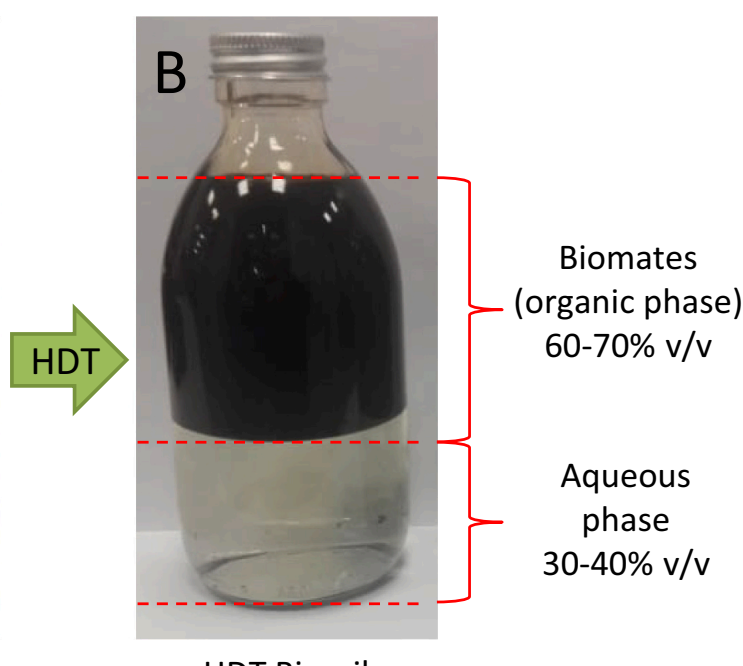

HDT Bio-oil

Picture 1. On the left (A) is the pure bio-oil feed and on the right (B) is the upgraded bio-oil after hydrotreatment (BioMates and aqueous phase).
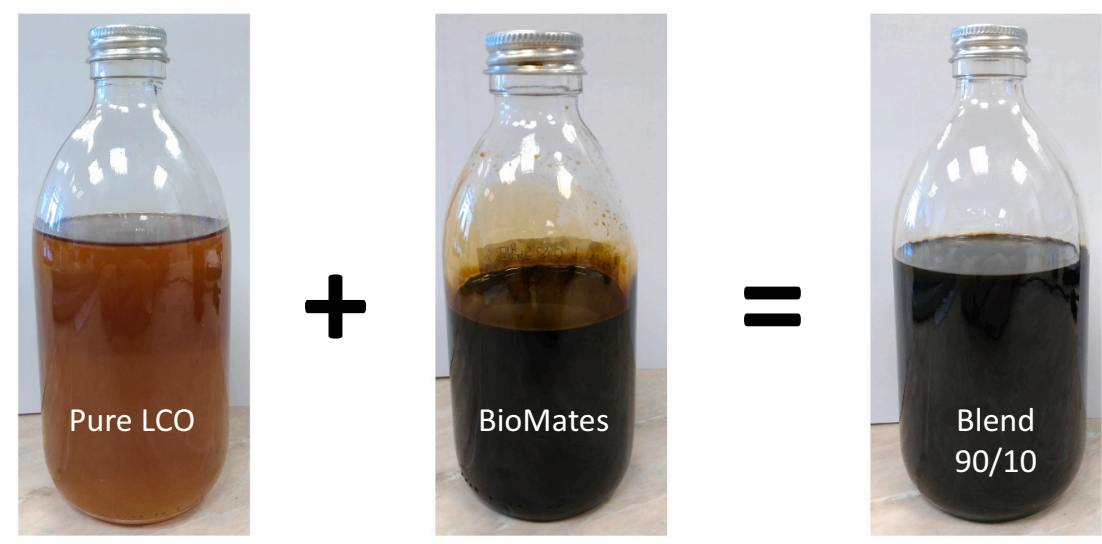

Picture 2. Pure LCO feed, BioMates and blend of 10/90 per volume BioMates/LCO.

volatile molecules compared to diesel (see Table 1). It is observed that, a hydrotreatment step is necessary to transform this bio-based feed into bio-based intermediate with more suitable quality characteristics for refinery integration. As a result, after a hydrotreatment upgraded step, the organic phase (BioMates) was characterized by almost zero oxygen, which was observed only in phenolic structures (Table 2), and thus low amount of dissolved water with improved TAN and reduced density compared to the AFP bio-oil. The BioMates used in the current study was a mixture of the best products in terms of oxygen content, from previous work [20].

Both the LCO and the BioMates contained higher boiling point fractions (Fig. 1), however each incorporated different hydrotreating challenges. LCO was characterized by lower density but higher sulphur content compared to BioMates. As a result, hydrotreating of LCO targeted to remove sulphur and polyaromatic hydrocarbons via hydrodesulphurization (HDS) and de-aromatization (HAD) reactions, respectively. On the other hand, BioMates was characterized by higher oxygen content and heavier molecules compared to LCO (Fig. 1). For this reason, the further hydrotreatment of BioMates targeted to remove the remaining oxygen via deoxygenation reactions (HDO) and also to crack the heavier molecules to lighter ones via cracking reactions.

For this study, three blends of BioMates and LCO were examined as they are presented in Table 1 . The addition of BioMates reduced the sulphur content of the blend, which was expected as BioMates is a low sulphur feed. Furthermore, the carbon content of the blend decreased with the increasing of BioMates. Another important observation is the effect of BioMates on the acidity (TAN) of the blend which increased with increasing BioMates content due to its higher acids content compared to LCO. Finally, BioMates is a more viscous stream compared to LCO, affecting negatively the blend viscosity. It should be noted that the BioMates/LCO blends contained no additives and were prepared in CPERI/CERTH, a few days prior to their utilization for the cohydroprocessing tests.

For the current study, a commercial $\mathrm{CoMo} / \mathrm{Al}_{2} \mathrm{O}_{3}$ catalyst was utilized, suitable for commercial upgrading of LCO-type feedstocks. The catalyst is a commercial catalyst that is used in the BP refinery for the LCO hydrotreatment, thus no further details can be provided about the type of the catalyst and its' main characteristics. The catalyst was used without any special manipulation (e.g., extrudate breaking) while it was diluted with silica carbide of 115 mesh. The silica carbide to catalyst ratio was 6.4:1 (wt\%). The catalyst presulfiding procedure was defined by the catalyst manufacturer.

\subsection{Experimental procedure}

In this study, three blends of BioMates and LCO were investigated while pure LCO was used as a reference. The operating window for cohydroprocessing was defined by BP a product potential end-user, based on a preliminary mapping of refinery process feedstocks' specifications, identifying potential BioMates entry points in underlying 
Table 1

Properties of Bio-oil, BioMates, LCO and various BioMates/LCO blends.

\begin{tabular}{|c|c|c|c|c|c|c|c|c|}
\hline \multirow[t]{2}{*}{ Properties } & \multirow[t]{2}{*}{ Units } & \multirow[t]{2}{*}{ Bio-oil } & \multirow[t]{2}{*}{ BioMates } & \multirow[t]{2}{*}{ LCO } & \multicolumn{3}{|c|}{ Blends BioMates/LCO $v / \mathrm{v}(\%)$} & \multirow[t]{2}{*}{ Analysis Method } \\
\hline & & & & & $10 / 90$ & $20 / 80$ & $30 / 70$ & \\
\hline Density at $288 \mathrm{~K}$ & $\mathrm{~g} / \mathrm{mL}$ & 1.024 & 0.927 & 0.924 & 0.925 & 0.925 & 0.926 & ASTM D-4052 \\
\hline Sulphur & wppm & 1183 & 428 & 8280 & 7620 & 6770 & 6040 & ASTM D-5453 \\
\hline Hydrogen & $\mathrm{wt} \%$ & 8.3 & 11.6 & 10.3 & $10.4^{*}$ & $10.6^{*}$ & $10.7^{*}$ & ASTM D-5291 \\
\hline Carbon & wt $\%$ & 53.9 & 85.4 & 88.5 & $88.2^{*}$ & $87.9 *$ & $87.6^{*}$ & ASTM D-5291 \\
\hline Oxygen & wt $\%$ & 37.0 & 2.1 & 0.2 & 0.5 & 0.7 & 0.9 & Calculated \\
\hline Nitrogen & ppm & 7000 & 6684 & 808 & 1463 & 2222 & 2471 & ASTM D-4629 \\
\hline $\mathrm{H}_{2} \mathrm{O}$ (dissolved) & wt $\%$ & 21.8 & 0.16 & 0.02 & 0.03 & 0.06 & 0.08 & ASTM D-1744 \\
\hline Viscosity & cSt & $>50$ & $4-8$ & 2.63 & 3.01 & 3.49 & 3.63 & ASTM D-445 \\
\hline MCR & wt $\%$ & 15.6 & 2.84 & 0.03 & 0.22 & 0.48 & 0.70 & ASTM D-4530 \\
\hline TAN & $\mathrm{mgKOH} / \mathrm{g}$ & 219 & 0.87 & 0.22 & 0.06 & 0.21 & 0.23 & ASTM D-664 \\
\hline Volatile phenolic compounds ${ }^{* *}$ & wt $\%$ & 8.48 & 5.40 & - & 0.54 & 0.95 & 1.39 & by GC-MS \\
\hline \multicolumn{9}{|l|}{ Distillation } \\
\hline 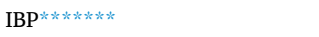 & $\mathrm{K}$ & - & 370 & 325 & 339 & 328 & 340 & \multirow{12}{*}{ ASTM D-7169 } \\
\hline $5 \mathrm{wt} \%$ & $\mathrm{~K}$ & - & 415 & 438 & 440 & 427 & 426 & \\
\hline $10 \mathrm{wt} \%$ & $\mathrm{~K}$ & - & 439 & 474 & 471 & 459 & 454 & \\
\hline $30 \mathrm{wt} \%$ & $\mathrm{~K}$ & - & 509 & 522 & 517 & 516 & 509 & \\
\hline $50 \mathrm{wt} \%$ & $\mathrm{~K}$ & - & 582 & 547 & 544 & 545 & 541 & \\
\hline $70 \mathrm{wt} \%$ & $\mathrm{~K}$ & - & 673 & 578 & 573 & 578 & 577 & \\
\hline $90 \mathrm{wt} \%$ & $\mathrm{~K}$ & - & 810 & 624 & 621 & 633 & 669 & \\
\hline $95 \mathrm{wt} \%$ & $\mathrm{~K}$ & - & 869 & 643 & 653 & 710 & 779 & \\
\hline $\mathrm{FBP}^{* * *}$ & $\mathrm{~K}$ & - & 984 & 693 & 791 & 940 & 959 & \\
\hline Gasoline (cut point $489 \mathrm{~K}$ ) & wt $\%$ & - & 25 & 14 & 15 & 17 & 20 & \\
\hline Diesel (cut point $616 \mathrm{~K}$ ) & wt $\%$ & - & 34 & 73 & 74 & 68 & 63 & \\
\hline Residue & wt $\%$ & - & 41 & 13 & 11 & 15 & 17 & \\
\hline
\end{tabular}

* Values of $\mathrm{C}$ and $\mathrm{H}$ for the three blends were calculated based on the proportion of LCO and HDT bio-oil content.

** Compounds containing phenol hydroxyl group including: phenols, methoxyphenols, dimethoxyphenols and benzenediols.

**** IBP: Initial boiling point.

${ }_{* * \cdots *}^{*}$ FBP: Final boiling point.

Table 2

Group composition of volatile fraction of bio-oil and BioMates determined by GC-MS.

\begin{tabular}{llll}
\hline Group of compounds & Units & Bio-oil & BioMates \\
\hline Carboxylic acids & wt $\%$ & 7.54 & 0 \\
Aldehydes & wt $\%$ & 0.36 & 0 \\
Ketones & wt $\%$ & 4.43 & 0 \\
Methoxyphenols & wt $\%$ & 4.31 & 0 \\
Phenols & wt $\%$ & 3.81 & 5.40 \\
Aromatics & wt $\%$ & 0.07 & 1.34 \\
n-Alkanes & wt $\%$ & 0 & 2.96 \\
Cycloalkenes & wt $\%$ & 0 & 0.22 \\
Cycloalkanes & wt $\%$ & 0 & 8.60 \\
\hline
\end{tabular}

refinery processes and targeted BioMates specifications for direct integration in refinery. To that aim, all the process parameters were remained constant, with the exception of reactor temperature which was gradually increased during the experiment (593-663 K) to maintain the products sulphur content at constant levels. More specifically, the reactor pressure was kept constant at $7 \mathrm{MPa}$, LHSV at $1 \mathrm{~h}^{-1}$ and $\mathrm{H}_{2}$ / liquid feed ratio at $500 \mathrm{NL} / \mathrm{L}$. $\mathrm{H}_{2}$ /liquid feed ratio defines the excess of hydrogen during the process.

For the current study, the TRL3 hydroprocessing pilot plant of CPERI/CERTH was employed. This TRL 3 pilot plant is a small-scale pilot plant incorporating the basic process characteristics of industrial hydroprocessing units, and is operated to generate information about the behavior of the hydroprocessing system used enabling the design of larger facilities. The plant consists of a stainless-steel continuous flow tubular reactor (15.8 $\mathrm{mm}$ I.D. and $704 \mathrm{~mm}$ in length) containing six independent heating zones. The temperature of each catalyst bed is monitored and controlled via the six independent thermocouples placed inside a thermo-well. The hydrogen flow-rate is regulated by a mass flow controller whereas the liquid feed system is regulated by a high-pressure liquid piston pump. The gaseous product flow-rate is measured by a wet- test meter and analyzed on-line via an Agilent 7890 series gas chromatograph analyzer. The current HDT unit allows testing in a targeted operating window, including reactor temperature (373-673 K), and pressure (4-13.5 MPa) and $\mathrm{H}_{2}$-to-liquid ratio (100-500 NL/L) simulating the industrial operating conditions of the refineries. The liquid feed rate during the experiment was $45 \mathrm{~mL} / \mathrm{h}$ while the hydrogen flow was $24.07 \mathrm{~L} / \mathrm{h}$ No further details will be provided as the plant is described in detail elsewhere [2,25-27].

\subsection{Analysis}

For the evaluation of the feed and liquid products, daily samples were collected and analyzed in the CPERI/CERTH analytical laboratory. Several analyses were performed for products as well as for the corresponding feed samples. Density was determined via ASTM D-4052, while the distillation curve was estimated according to the Simulated Distillation ASTM D-7169 procedure. The concentration of sulphur and nitrogen in the feed and liquid products was determined by the ASTM D5453 and ASTM D-4629 analysis respectively. Hydrogen and carbon content were determined via the ASTM D-5291 method. Once total carbon, hydrogen, nitrogen and sulphur content ( $\mathrm{wt} \%$ ) were determined, the oxygen concentration was indirectly calculated assuming negligible concentration of all other elements in the product. The dissolved water concentration was determined via the ASTM D-1744, total acid number (TAN) via the ASTM D-664 and kinematic viscosity via the ASTM D-445 analysis. Cetane index of the products was calculated based on density measurement (at $15{ }^{\circ} \mathrm{C}$ ) and the distillation curve. MicroConradson carbonization residue (MCR) was determined in agreement with ASTM D-4530. Bromine number was measured according to ASTM D-1159. The amount of mono-, di- and poly- aromatics was quantified by HPLC-RI method used for diesel characterization in agreement with EN 12916. Quantification of volatile compounds was carried out by GC-MS. Samples were dissolved in acetone $(\approx 1: 20 \mathrm{w} / \mathrm{w}), 1$-butoxypropan-2-ol and 2-naphthaldehyde were used as internal standards. Dissolved 


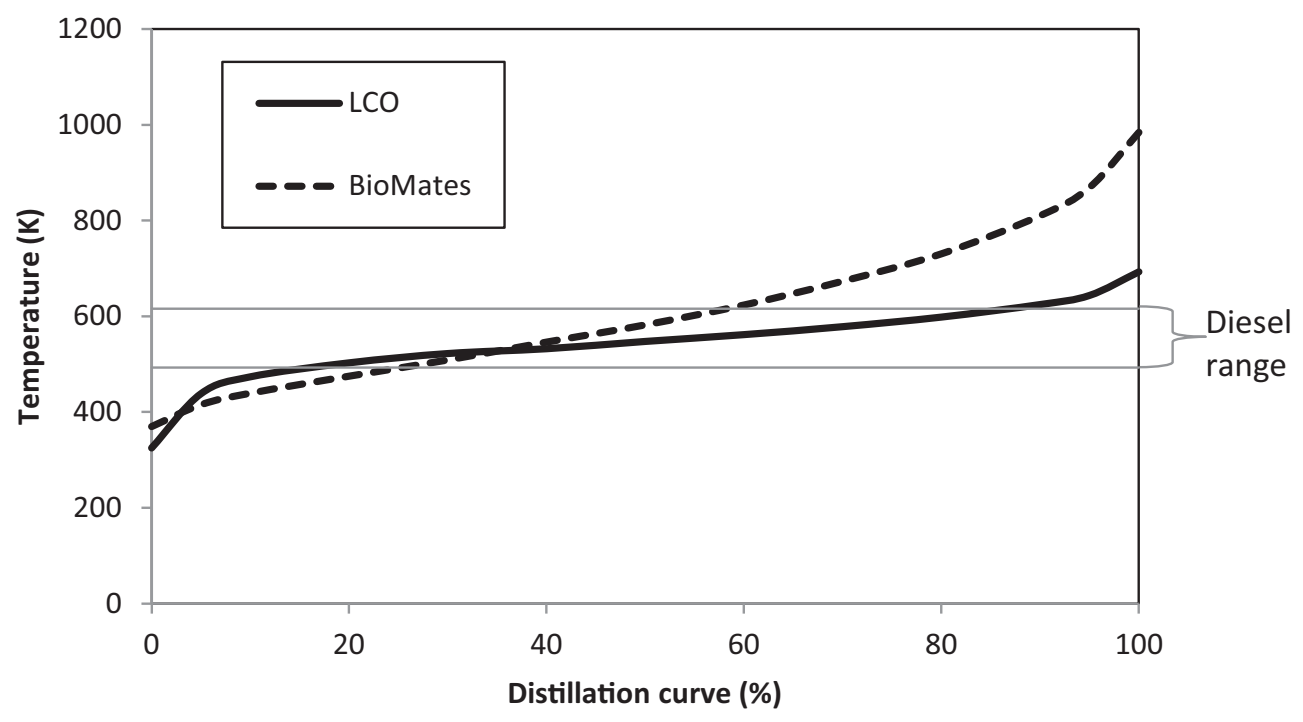

Fig. 1. Mass recovery of LCO and BioMates.

samples $(1 \mu \mathrm{L})$ were injected into the injector $(523 \mathrm{~K})$ at split 1:20 with helium as a carrier gas at a constant flow rate of $1.0 \mathrm{~mL} \cdot \mathrm{min}^{-1}$. The sample was separated over ZB-5MSi column. The temperature program of the oven was started at $305 \mathrm{~K}$ with an 8 min hold time followed by ramping the temperature at $278 \mathrm{~K} \cdot \mathrm{min}^{-1}$ up to $573 \mathrm{~K}$ with an $10 \mathrm{~min}$ hold time. More than 100 compounds were quantified directly and other around 100 were quantified indirectly using the response factor of structurally most similar compound in the standard. The method was in detail described elsewhere [25]. Finally, the gaseous product was analyzed on-line via an Agilent 7890 series gas chromatograph analyzer, equipped with one flame ionization detector and two thermal conductivity detectors. The gaseous product concentration enabled the mass balances calculations and the $\mathrm{H}_{2}$ balance calculations.

\section{Results and discussion}

\subsection{Effect of BioMates on catalyst life expectancy}

The investigation of the catalyst deactivation was monitored via the reactor $\Delta \mathrm{P}$ and the sulphur content of the daily product. The propagation of $\Delta \mathrm{P}$ vs time during testing is presented in Fig. 2, showing that the reactor $\Delta \mathrm{P}$ was stable during the whole experiment, indicating no clogging of the catalyst bed for the whole 37 DOS (Days On Stream). In general, phenols and furans that exist on the bio-oil, interact with the catalytic surface and lead to coke formation and catalyst blocking [28]. In addition, minerals can also lead to catalyst poisoning, while aldehydes ketones and sugars can lead to the production of tar-like products that can also block the catalyst [29]. However, due to the hydrotreatment upgrading step of bio-oil, the initial oxygenates were transformed to their corresponding alcohols resulting in a more stable feed [20]. As a result, neither clogging nor permanent loss of catalyst effectiveness was observed after 37 DOS, with the introduction of BioMates, indicating that it is not expected a rapid fouling with the integration of BioMates in LCO stream of a typical hydrotreating unit.

The co-hydroprocessing testing overview of product sulphur content variation for all feeds (LCO/BioMates ratio) tested and corresponding reactor temperature variation are presented in Fig. 3 . When the presulphiding of the catalyst was completed, pure LCO (100\%) was introduced (DOS 1, Fig. 3) for three consecutive days, as a catalyst stabilization procedure and also as a reference condition. On the 3rd DOS, the first blend with $10 \%$ BioMates was introduced into the unit and was tested for 6 consecutive days (DOS 4-9). The aim was to investigate how the $10 \%$ BioMates influenced the HDS activity of the catalyst. As sulphur content of hydrotreated product increased upon BioMates addition to LCO, it was concluded that the BioMates had a negative effect on the catalyst HDS activity. To counteract this effect, temperature

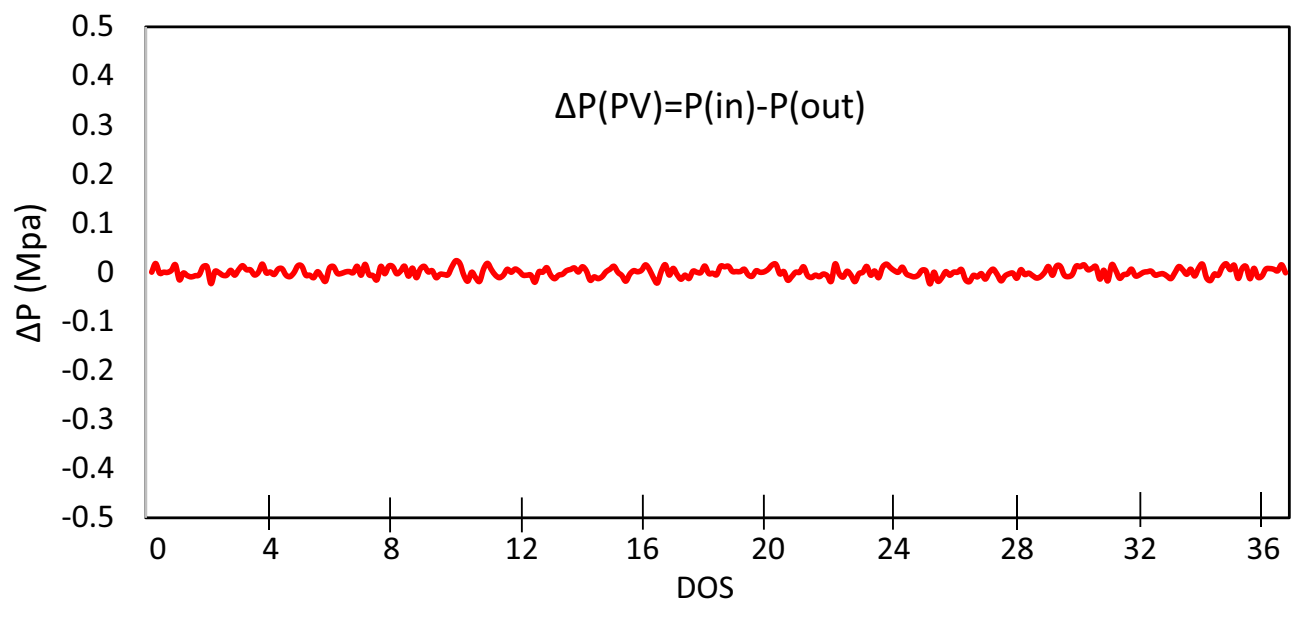

Fig. 2. $\Delta \mathrm{P}$ plot during co-processing testing run ( $\Delta \mathrm{P}$ vs $\mathrm{DOS})$. 


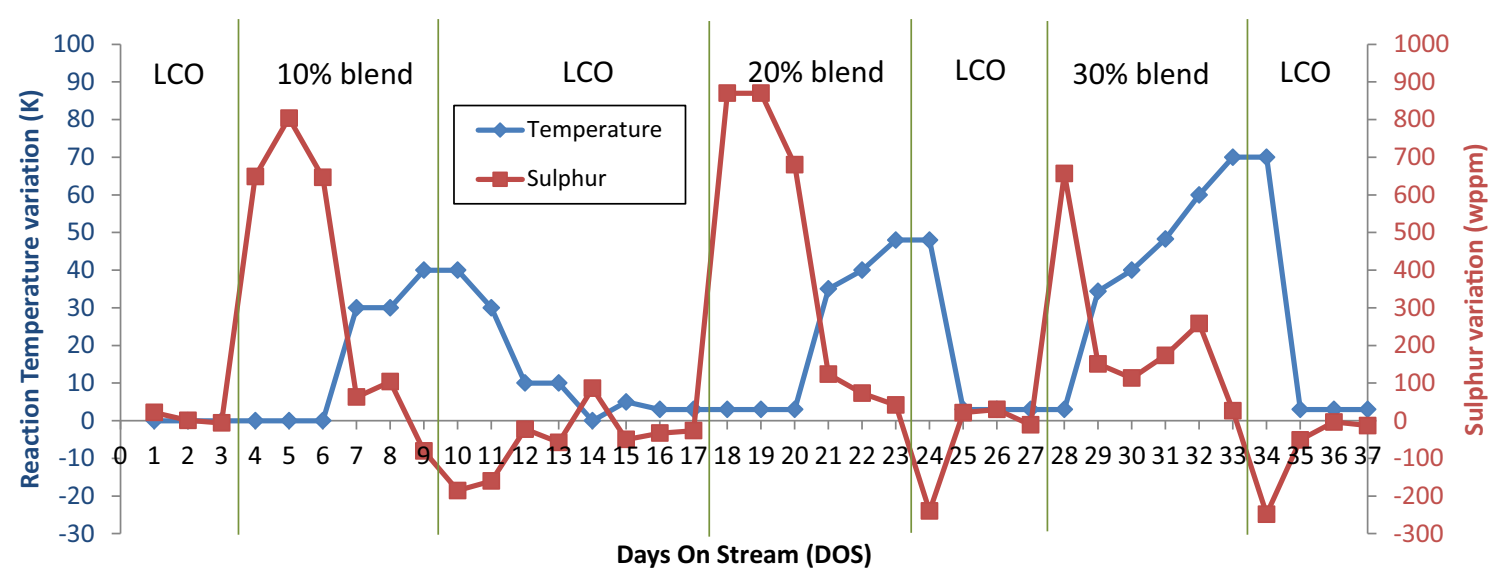

Fig. 3. Co-processing testing overview of product sulphur content variation for all feeds tested and corresponding reactor temperature variation.

was gradually increased to maintain product sulphur content at constant levels, without deviating from the reference levels on the 3rd DOS with neat LCO. On the 9th DOS pure LCO was again introduced into the unit as a reference for comparison purposes. The aim was to find the lowest temperature where the same sulphur content with the control condition (pure LCO) could be achieved. Thus, the permanent deactivation of the catalyst could be determined in terms of reaction temperature and HDS efficiency. Then the second blend with $20 \%$ BioMates was introduced (DOS 17) and the same procedure was followed for both $20 \%$ and $30 \%$ blends per volume, after each run with different feed the LCO control condition was repeated.

The following Table 3 presents the permanent as well as the temporary HDS catalyst inhibition for each case (each blend) in terms of temperature (K). According to Fig. 3 and Table 3, the addition of BioMates in LCO feed influenced the HDS (hydrodesulphurization) efficiency of the catalyst and more specifically the increase in BioMates content increased the catalyst inhibition. However, the inhibition was only temporary as after the removal of BioMates from the feed the catalyst performance almost returned to its initial stage (as it was with neat LCO on the 3rd DOS).

\subsection{Product evaluation}

The properties of the products for each blend are presented in Table 4, where the inhibition effect on HDS reactions was also confirmed from the gas product analysis due to the lower $\mathrm{H}_{2} \mathrm{~S}$ content observed for the blends compared to neat LCO. However, the deactivation of the catalyst was only temporary, as the HDS efficiency of the catalyst returned to almost initial activity with neat LCO after the removal of BioMates from the feed (Fig. 3). The co-hydroprocessing of BioMates outcomes are in agreement with similar studies in the open literature [12,14-19] testing crude bio-oil or pure oxygenated compounds coprocessing. The inhibition effect on HDS reactions that was observed in the presence of BioMates fraction was due to the competitive absorption of phenols contained in BioMates that took place at the same active sites of the catalyst used for HDS reactions for LCO. The cracking

Table 3

Effect of BioMates content on catalyst HDS efficiency expressed in terms of temperature $(\mathrm{K})$ needed to achieve same sulphur removal (temporary and permanent HDS inhibition).

\begin{tabular}{lll}
\hline BioMates content in LCO feed $\% v / \mathrm{v}$ & \multicolumn{2}{l}{ Inhibition effect in HDS efficiency in K } \\
\cline { 2 - 3 } & Temporary & Permanent \\
\hline $10 \%$ blend & 40 & 3 \\
$20 \%$ blend & 45 & 3 \\
$30 \%$ blend & 67 & 3 \\
\hline
\end{tabular}

Table 4

Properties of products obtained from the co-processing testing of the three LCO/ BioMates blends and pure LCO.

\begin{tabular}{|c|c|c|c|c|c|}
\hline Properties & Units & $\begin{array}{l}100 \% \\
\text { LCO }\end{array}$ & $\begin{array}{l}\text { 10/90 } \\
\text { BioMates/ } \\
\text { LCO }\end{array}$ & $\begin{array}{l}20 / 80 \\
\text { BioMates/ } \\
\text { LCO }\end{array}$ & $\begin{array}{l}30 / 70 \\
\text { BioMates/ } \\
\text { LCO }\end{array}$ \\
\hline $\begin{array}{c}\text { Density at } \\
288 \mathrm{~K}\end{array}$ & $\mathrm{~g} / \mathrm{mL}$ & 0.8977 & 0.8985 & 0.8985 & 0.8950 \\
\hline Sulphur* & wppm & 293.9 & 219.4 & 341.4 & 326.4 \\
\hline Hydrogen* & wt $\%$ & 11.43 & 11.37 & 11.68 & 11.71 \\
\hline Carbon* & wt $\%$ & 88.44 & 88.67 & 88.32 & 89.28 \\
\hline $\mathrm{H} / \mathrm{C}$ ratio & - & 0.129 & 0.128 & 0.132 & 0.131 \\
\hline Nitrogen* & wppm & 44 & 359 & 730 & 568 \\
\hline Oxygen* & $\mathrm{wt} \%$ & 0.00 & 0.00 & 0.00 & 0.00 \\
\hline $\begin{array}{l}\text { Water } \\
\text { content }\end{array}$ & wt $\%$ & 0.0012 & 0.0020 & 0.0013 & 0.0100 \\
\hline MCR & wt $\%$ & $<0.01$ & 0.04 & 0.08 & 0.09 \\
\hline TAN & $\begin{array}{l}\text { mgKOH/ } \\
\mathrm{g}\end{array}$ & 0 & 0 & 0.01 & 0.01 \\
\hline Viscosity & cSt & 2.894 & 3.004 & 2.715 & 2.598 \\
\hline $\begin{array}{l}\text { Bromine } \\
\text { number }\end{array}$ & $\begin{array}{l}\mathrm{gBr}_{2} / \\
100 \mathrm{~g}\end{array}$ & 0.41 & 1.10 & 1.67 & 1.68 \\
\hline $\begin{array}{l}\text { Volatile } \\
\text { phenols by } \\
\text { GC-MS }\end{array}$ & wt $\%$ & 0 & 0 & 0 & 0 \\
\hline Cetane Index & - & 31.5 & 31.8 & 32.0 & 32.5 \\
\hline \multicolumn{6}{|l|}{ Distillation } \\
\hline $\mathrm{IBP}^{* * *}$ & $\mathrm{~K}$ & 387 & 376 & 374 & 364 \\
\hline $10 \mathrm{wt} \%$ & $\mathrm{~K}$ & 473 & 462 & 456 & 443 \\
\hline $30 \mathrm{wt} \%$ & $\mathrm{~K}$ & 512 & 510 & 509 & 503 \\
\hline 50 wt $\%$ & $\mathrm{~K}$ & 538 & 538 & 538 & 537 \\
\hline $70 \mathrm{wt} \%$ & $\mathrm{~K}$ & 569 & 571 & 574 & 574 \\
\hline $90 \mathrm{wt} \%$ & $\mathrm{~K}$ & 615 & 622 & 630 & 636 \\
\hline $\mathrm{FBP}^{* * *}$ & $\mathrm{~K}$ & 689 & 759 & 784 & 786 \\
\hline \multicolumn{6}{|c|}{ Gas product content } \\
\hline Hydrogen & $\mathrm{g} / \mathrm{h}$ & 1.540 & 1.728 & 1.555 & 1.550 \\
\hline Methane & $\mathrm{g} / \mathrm{h}$ & 0.002 & 0.004 & 0.025 & 0.064 \\
\hline Ethane & $\mathrm{g} / \mathrm{h}$ & 0.004 & 0.005 & 0.038 & 0.091 \\
\hline Propane & $\mathrm{g} / \mathrm{h}$ & 0.014 & 0.014 & 0.030 & 0.063 \\
\hline Isobutane & $\mathrm{g} / \mathrm{h}$ & 0.013 & 0.012 & 0.009 & 0.012 \\
\hline N-butane & $\mathrm{g} / \mathrm{h}$ & 0.017 & 0.018 & 0.022 & 0.035 \\
\hline Isopentane & $\mathrm{g} / \mathrm{h}$ & 0.019 & 0.020 & 0.017 & 0.016 \\
\hline $\mathrm{H}_{2} \mathrm{~S}$ & $\mathrm{~g} / \mathrm{h}$ & 0.259 & 0.213 & 0.172 & 0.110 \\
\hline
\end{tabular}

* dry basis.

*** IBP: Initial boiling point.

FB: FP: Final boiling point.

reactions of rest pyrolytic lignin molecules were well demonstrated by the significant reduction of MCR almost fulfilling the EN 590 standard (Table 4). 
According to Table 4, there are no strong differences in the product properties among the three examined blends compared to hydrotreated neat LCO. This is a particularly promising result indicating that the addition of BioMates up to $30 \%$ per volume did not reduce the quality of the final product. The final product was characterized by low density close to the diesel range $(0.820-0.845 \mathrm{~g} / \mathrm{mL})$ [30], reduced sulphur content, almost zero oxygen and water content, low Bromine number, high $\mathrm{H} / \mathrm{C}$ ratio and low viscosity fulfilling the EN 590 standard.

As far as the gas product analysis is concerned, the most important differences were observed in the formation of methane, ethane, propane and $\mathrm{H}_{2} \mathrm{~S}$ (Table 4). Methane, ethane and propane were the products of phenols dealkylation and cracking reactions [31], while $\mathrm{H}_{2} \mathrm{~S}$ was the product from HDS reactions. The addition of BioMates in LCO feed, led to higher methane, ethane and propane production due to its phenol and hydrocarbon content. In addition, the lower $\mathrm{H}_{2} \mathrm{~S}$ gaseous product observed with the addition of BioMates in LCO is attributed to two main reasons. Firstly, the BioMates is a nearly sulphur-free feed and thus its addition reduces the total sulphur content of the blend (BioMates/LCO) compared to neat LCO, rendering lower HDS activity and lower $\mathrm{H}_{2} \mathrm{~S}$ gaseous products. Secondly, the aromatics and also phenolics of BioMates, are adsorbed strongly in the same active sites of the catalyst for HDS reactions and thus the HDS reactions are inhibited.

Regarding the composition of the liquid products, the monocyclic compounds with different alkyl substituents are the main structural motif coming from the lignin molecules and thus their content increased with increasing BioMates ratio in the feed (Fig. 4 A-D). Comparing the amounts of these structures in products from co-hydroprocessing is therefore a good guide for considerations on the transformation of phenols during this process. Based on the results from GC-MS, the phenols were probably during the deoxygenation transformed into another type of molecules e.g., respective cyclopentanes or non-cyclic alkanes (Fig. 4 A-C, the decrease of content in comparison to feed). Only propyl monocyclic compounds were observed in higher content in products showing that these structures were probably created by cracking of pyrolytic lignin molecules (Fig. 4 D). Increasing cracking with increased reaction temperature was also observed on the example of n-alkanes, which well visible on the significant increase in n-octane content in the product from $30 \%$ blend (Fig. S1). Comparing feed and products the increase of n-alkanes with 8-26 carbon atoms was observed with n-pentadecane as the most abundant $\mathrm{n}$-alkane in products.

Apart from HDS, the aim of LCO hydrotreatment is also the reduction of the content of polyaromatic compounds that are limited in diesel fuel and also to increase the cetane number which is poor for aromatics. As can be observed in Fig. 5, the hydrotreatment decreased the polyaromatic hydrocarbons (PAH; in EN 590 defined as total aromatics content minus the monoaromatics content) content of LCO below the EN 590 limit (8\% per weight). PAH are not typical structures in BioMates, and thus, its addition to LCO definitely decreased the initial PAH content of co-process feed. Despite, we observed gradually increasing content of $\mathrm{PAH}$ in products with increasing ratio of BioMates in feed. Based on these results we can state that the addition of BioMates to LCO suppress the hydrogenation of PAH. However, the increase in PAH content was very slight and the mixing with low aromatics diesel fraction like HDS SRGO could help to meet the PAH limit. Aromatics have a low cetane number and co-hydroprocessing of BioMates have positive effect on cetane number of hydrotreated LCO as BioMates is full of saturated hydrocarbons with high cetane number. The total aromatics content of hydrotreated $30 \%$ blend was reduced by $12 \%$ per weight compared to pure LCO hydrotreatment (Fig. 5) which is also confirmed by the increase of cetane index (Table 4) with the increase of Biomates content in the blend.

The higher aromatics content in product $\mathrm{P}(100 / 0)$ compared to LCO
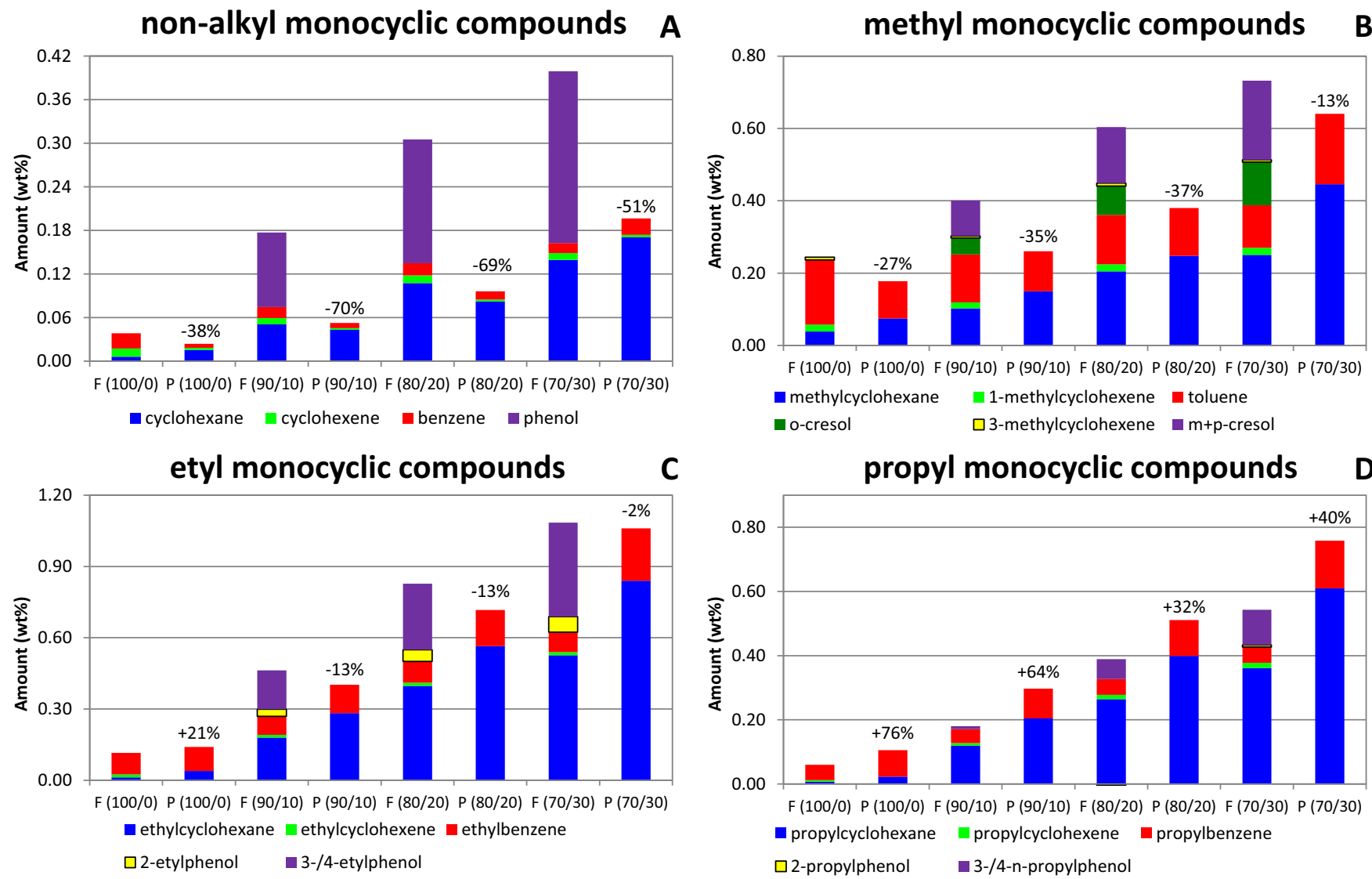

Fig. 4. Monocyclic compounds with different alkyl substituents (A) non-alkyl, (B) methyl, (C) etyl, (D) propyl. $\mathrm{F}=$ feed, $\mathrm{P}=$ product, in brackets ratio of LCO/ BioMates, above the bar of products marked a percentage increase or decrease in comparison to feed. 


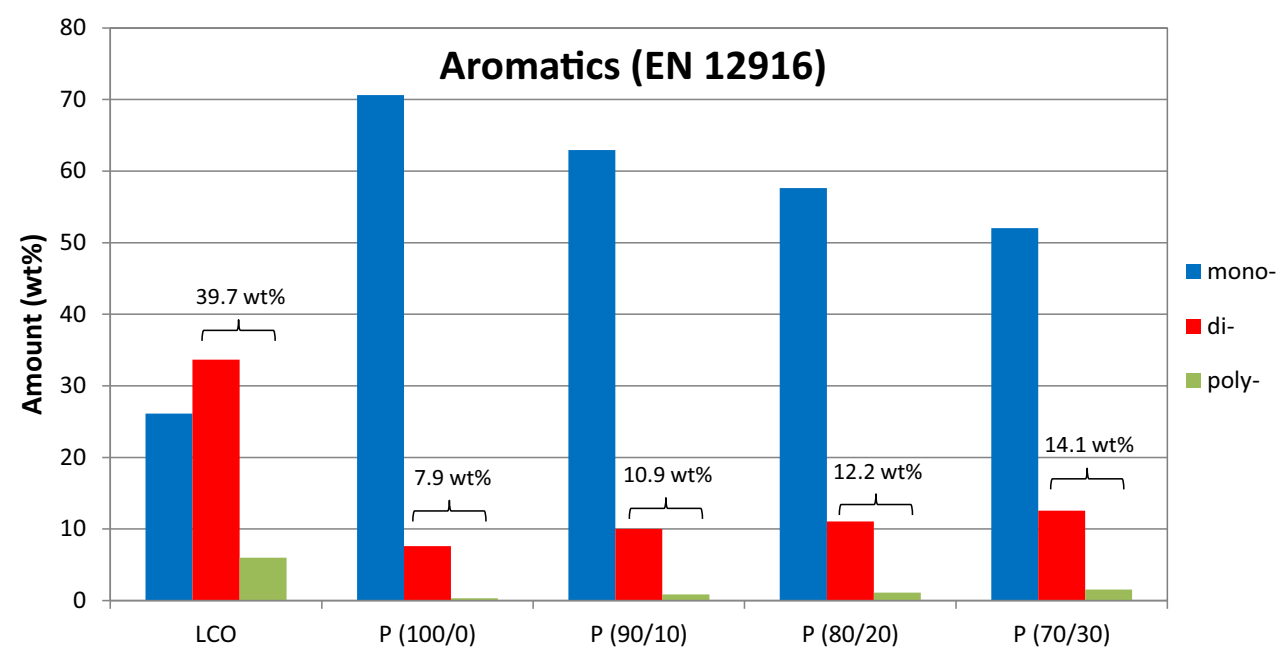

Fig. 5. The total aromatics content determined by HPLC-RI according to EN 12916.

can be attributed to the inability of used method to determine accurately the content of monoaromatics in LCO hydrotreated products. This method is intended for diesel analysis and o-xylene is used as a standard for monoaromatics determination that are preferably represented by similar monocyclic structures. However, tetralines with higher response are the preferably created monoaromatics from LCO hydrotreatment, which leads to falsely higher monoaromatics content. Despite this unfavorable fact, the results reflect well the suppression of PAH hydrogenation.

Mass recovery curves of the products are juxtaposed in Fig. 6 indicating the effect of BioMates content on diesel and gasoline yields. Two actual cut-points were considered, cut point was for gasoline at $489 \mathrm{~K}$, for diesel at $633 \mathrm{~K}$ and remaining product was the heavier $\mathrm{HC}$ fraction.

For pure LCO, the diesel and gasoline yield were $73.8 \%$ and $16.5 \%$ per weight, respectively. The processing of $30 \%$ blend resulted in decrease in diesel yield to $62.4 \%$ per weight on the other hand increase in gasoline yield to $23.2 \%$ per weight was observed. The addition of BioMates in LCO feed slightly increased the yields of the heavier products, however the variation was very small (less than $5 \%$ per weight). From the findings, it was observed that the final products from cohydroprocessing characterized by diesel and gasoline range hydrocarbons could be used as a hybrid transportation fuel.

The changes of the products' color with the addition of BioMates are depicted on Picture 3. However, as it was discussed previously, the properties of the products present no significant differences with the addition of the BioMates in the feed except for the increased end of distillation.

\subsection{Process efficiency}

The overall process efficiency was also investigated for each blend. The process efficiency is presented in Fig. 7 in terms of volume based liquid product yields and was calculated according to the following Eq. (1):

Liquid product yield $=100-\frac{\text { Liquid Product }_{(l / h)}-\text { Liquid feed }_{(l / h)} * 100}{\text { Liquid feed }_{(l / h)}} * 1$

The neat LCO yields are indicated by number 1 , while the yields resulting from the 10/90, 20/80 and 30/70 per volume BioMates/LCO blends are indicated by numbers 2,3 and 4 respectively. The overall efficiency was above $96 \%$ per volume for all tested blends, with the individual deviation close to measurements efficiency. From the current analysis, it was observed that the addition of BioMates up to $30 \%$ per volume resulted in similar or slightly higher volume-based product yields compared to neat LCO. The water phase slightly increased as the percent of BioMates in the feed increased, however, in all cases the amount of water phase produced via co-processing was below $1 \%$ per volume. This was expected as the BioMates is characterized by limited oxygen content and negligible amounts of dissolved water (Table 1). This yield comparison is very important towards the potential commercialization of the technology, as it indicates that the integration of the BioMates in LCO does not influence the efficiency of the overall process.
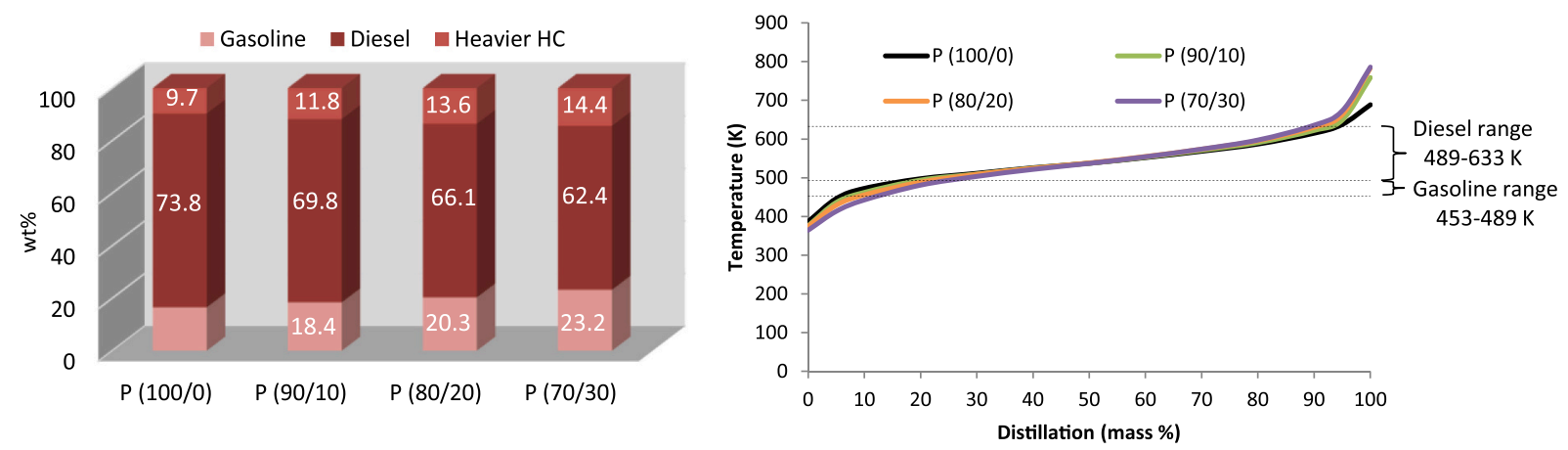

Fig. 6. Distillation of organic liquid products from HDT of 100\% LCO and various blends of LCO/BioMates ( $v / v)$. 

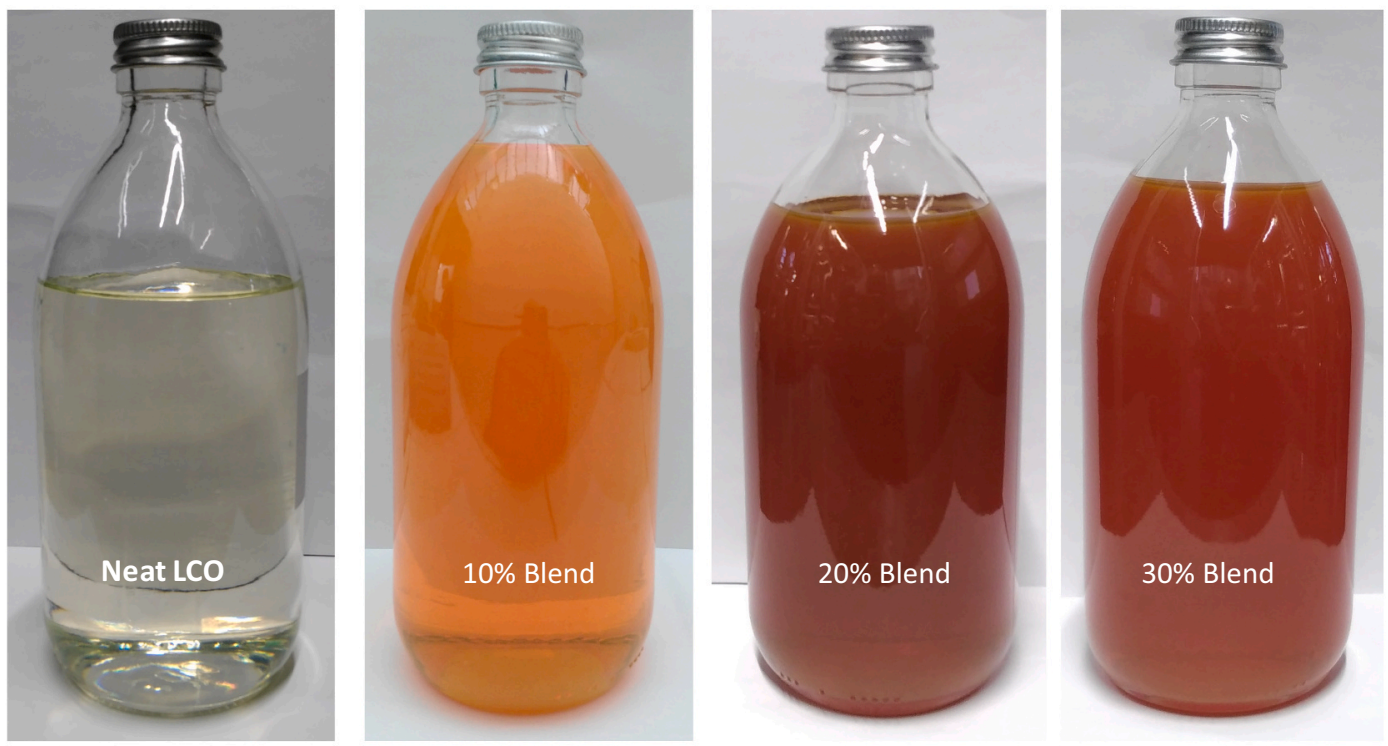

Picture 3. Products from neat LCO and BioMates/LCO blends: $10 \%, 20 \%$ and $30 \%$ per volume BioMates content.

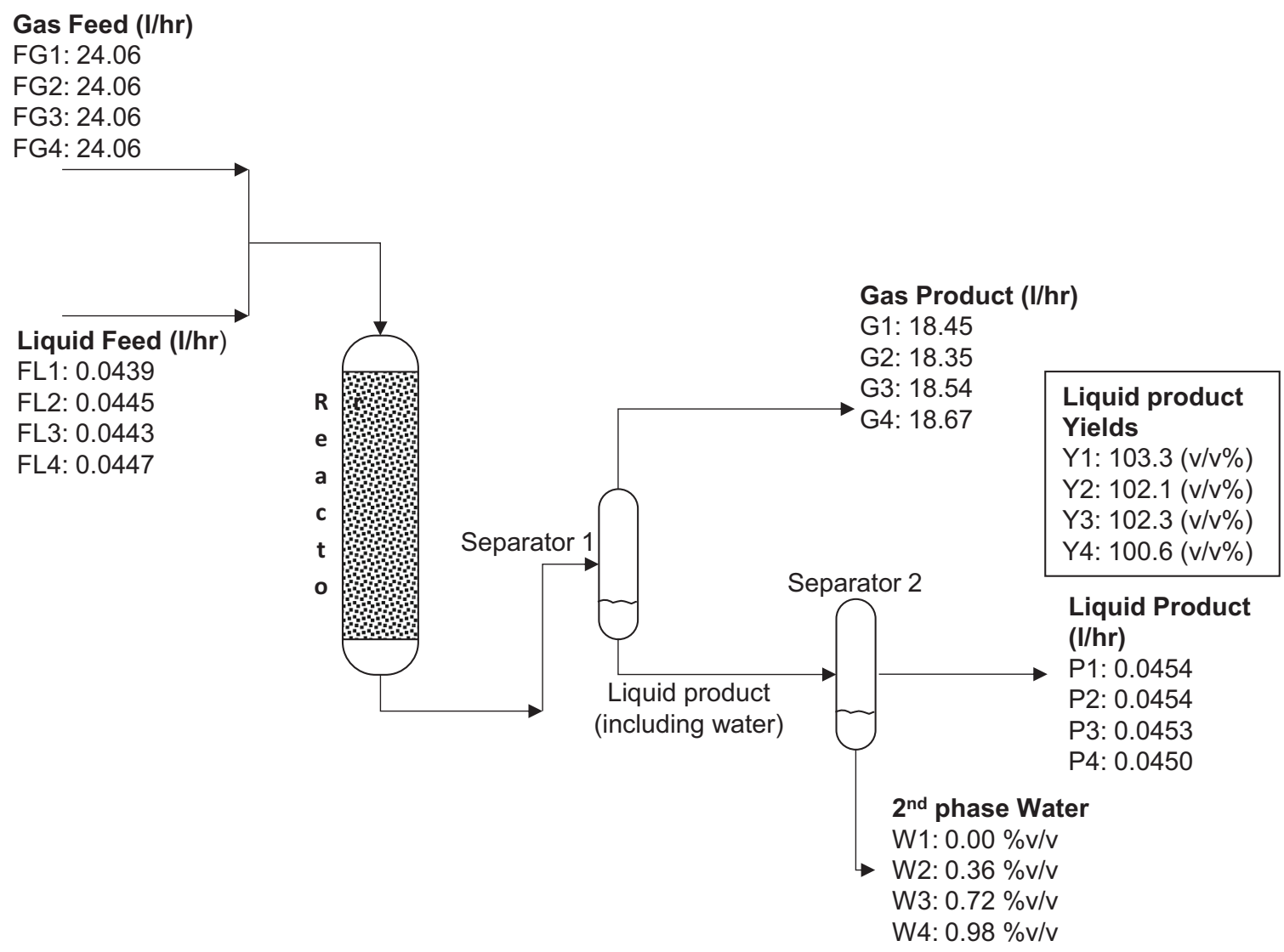

Fig. 7. Process flow and yields per volume (1: 0/100 per volume BioMates/LCO, 2: 10/90, 3: 20/80 and 4: 30/70).

\subsection{Hydrogen consumption}

Hydrogen consumption of the co-hydroprocessing process plays an important role from an economic perspective. The effect of BioMates integration in an existing LCO hydrotreating process on hydrogen consumption is presented in Fig. 8. The methodology for the hydrogen consumption calculation is deeply described in an author's previous work [20].

According to the experimental results, the addition of BioMates led to lower hydrogen consumption by 7.8 to $8.9 \%$, in comparison with neat LCO, which was systematically observed for all three BioMates/LCO blends. This is, firstly, due to the very low sulphur content of BioMates which reduced the sulphur content of the blend as compared with the sulphur content of neat LCO and secondly, due to the difference in 


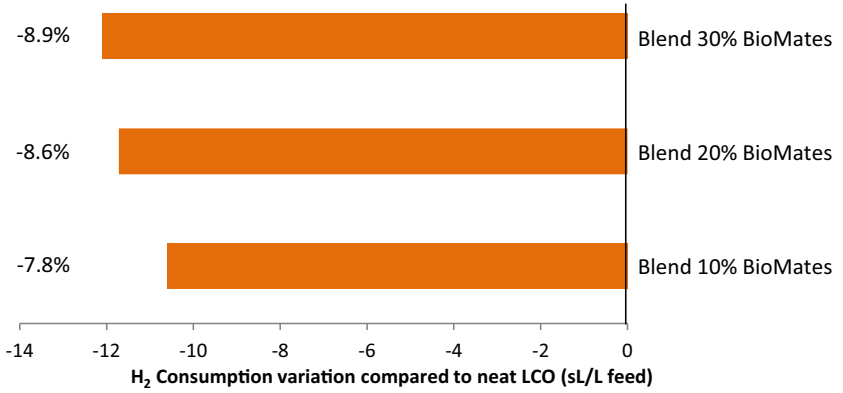

Fig. 8. Effect of BioMates content on hydrogen consumption $\left(\mathrm{H}_{2}\right.$ consumption variation of BioMates/LCO blends compared to pure LCO) (Standard liter per liter feed, STP is defined as a temperature of $273.15 \mathrm{~K}$ and an absolute pressure of $100 \mathrm{kPa}$ ).

hydrogenation of aromatics. This led to a reduction of hydrogen consumption due to the less hydrodesulphurization (HDS) reactions that take place during the process which was also confirmed from the gas product analysis presented in section 3.2. However, parallel reactions such as hydrodenitrogenation (HDN), hydrodeoxygenation (HDO) and cracking proceeded due to increased oxygen and nitrogen content after BioMates addition and necessity to increase the temperature to reach required sulphur content. As a result, the integration of BioMates content in pure LCO can bring economic benefits in a refinery from hydrogen consumption view point.

\section{Conclusions}

The purpose of the manuscript was to investigate the potential of integrating the organic phase of a hydrotreated pyrolysis bio-oil, called BioMates, in underlying refineries by co-hydroprocessing it with a petroleum fraction, rendering BioMates a reliable renewable refinery cofeed towards the production of a hybrid transportation fuel. BioMates was blended with Light Cycle Oil (LCO) at three ratios (10\%, 20\% and $30 \%$ per volume BioMates content). The results have shown that the integration of BioMates as a co-feed in LCO hydrotreatment:

- results in a liquid product consisting of diesel- and gasoline-range hydrocarbons with negligible water and oxygen content, low viscosity and TAN,

- allowed normal operation as no $\Delta \mathrm{P}$ build-up was observed during the 37-day-long tests, indicating negligible coke formation or process efficiency losses,

- reduced hydrogen consumption by up to $8.9 \%$ compared to standalone LCO hydroprocessing, thus not raising any economic concerns,

- is associated with inhibition in terms of HDS activity, which however can be overcome by increasing the reaction temperature.

The current approach provides a profound insight into the integration of an upgraded bio-oil (BioMates) in an existing LCO hydrotreatment refinery unit for future research on potential production of hybrid fuels via co-hydroprocessing of stabilized bio-based pyrolysis oil and petroleum streams.

Supplementary data to this article can be found online at https://doi. org/10.1016/j.fuproc.2022.107220.

\section{CRediT authorship contribution statement}

Athanasios Dimitriadis: Formal analysis, Investigation, Writing original draft. George Meletidis: Data curation. Ulrich Pfisterer: Resources, Validation. Miloš Auersvald: Formal analysis. David Kubička: Methodology, Formal analysis. Stella Bezergianni: Conceptualization, Funding acquisition, Project administration.

\section{Declaration of Competing Interest}

The authors declare that they have no known competing financial interests or personal relationships that could have appeared to influence the work reported in this paper.

\section{Acknowledgement}

The authors wish to express their appreciation for the financial support provided by European Union's Horizon 2020 research and innovation program under grant agreement No 727463 for the project "BioMates". Furthermore, the authors thank the BP Rotterdam refinery in Netherlands for providing the LCO feed and catalyst samples.

\section{References}

[1] A. Zacher, M. Olarte, D. Santosa, D.C. Elliot, B. Jones, A review and perspective of recent bio-oil hydrotreating research, Green Chem. 16 (2014) 491-515, https:// doi.org/10.1039/C3GC41382A.

[2] S. Bezergianni, A. Dimitriadis, O. Kikhtyanin, D. Kubička, Refinery co-processing of renewable feeds, Prog. Energy Combust. Sci. 68 (2018) 29-64, https://doi.org/ 10.1016/j.pecs.2018.04.002.

[3] A.H. Bhatt, Y. Zhang, G. Heath, Bio-oil co-processing can substantially contribute to renewable fuel production potential and meet air quality standards, Appl. Energy 268 (2020), 114937, https://doi.org/10.1016/j.apenergy.2020.114937.

[4] X. Ma, S. Pang, Q. Xu, Kinetic study of carbonaceous deposit formation and catalyst deactivation in hydrotreating of fast pyrolysis bio-oil, Chem. Eng. Sci. 231 (2021), 116316, https://doi.org/10.1016/j.ces.2020.116316.

[5] H. Wang, P.A. Meyer, D.M. Santos, C. Zhu, M.V. Olarte, S.B. Jones, A.H. Zacher, Performance and techno-economic evaluations of co-processing residual heavy fraction in bio-oil hydrotreating, Catal. Today 365 (2020) 357-364, https://doi. org $/ 10.1016 /$ j.cattod.2020.08.035.

[6] F.D. Mercader, M.J. Groeneveld, S.R.A. Kersten, N.W.J. Way, C.J. Schaverien, J. A. Hogendoorn, Production of advanced biofuels: co-processing of upgraded pyrolysis oil in standard refinery units, Appl. Catal. B-Environ 96 (2010) 57-66, https://doi.org/10.1016/j.apcatb.2010.01.033.

[7] Y.C. Lin, G.W. Huber, The critical role of heterogeneous catalysis in lignocellulosic biomass conversion, Energy, Environ. Sci. 2 (2009) 68-80, https://doi.org/ 10.1039/B814955K.

[8] F.D. Mercader, M.J. Groeneveld, S.R.A. Kersten, R.H. Venderbosch, J. A. Hogendoorn, Pyrolysis oil upgrading by high pressure thermal treatment, Fuel 89 (2010) 2819-2837, https://doi.org/10.1016/j.fuel.2010.01.026.

[9] Q. Cai, T. Yu, S. Zhang, Enhanced aromatic hydrocarbon production from bio-oil hydrotreating-cracking by Mo-Ga modified HZSM-5, Fuel 269 (2020), 117386, https://doi.org/10.1016/j.fuel.2020.117386.

[10] M. Auersvald, B. Shumeiko, D. Vrtiška, P. Straka, M. Staš, P. Šimáček, J. Blažek, D. Kubička, Hydrotreatment of straw bio-oil from ablative fast pyrolysis to produce suitable refinery intermediates, Fuel 238 (2019) 98-110, https://doi.org/10.1016/ j.fuel.2018.10.090.

[11] A. Pinheiro, D. Hudebine, N. Dupassieux, N. Charon, C. Geantet, Membrane fractionation of biomass fast pyrolysis oil and impact of its presence on a petroleum gas oil hydrotreatment, Oil Gas Sci. Technol. - Rev. IFP Energies Nouvelles 68 (2013) 815-828, https://doi.org/10.2516/ogst/2013124.

[12] A. Pinheiro, D. Hudebine, N. Dupassieux, C. Geantet, Impact of Oxygenated Compounds from Lignocellulosic Biomass Pyrolysis oils on Gas Oil Hydrotreatment, Energy Fuel 23 (2009) 1007-1014, https://doi.org/10.1021/ ef800507z.

[13] F.D. Mercader, M.J. Groeneveld, S.R.A. Kersten, C. Geantet, G. Toussaint, N.W. J. Way, C.J. Schaverienc, K.J.A. Hogendoorn, Hydrodeoxygenation of pyrolysis oil fractions: process understanding and quality assessment through co-processing in refinery units, Energy Environ. Sci. 3 (2011) 985, https://doi.org/10.1039/ COEE00523A.

[14] V.N. Bui, G. Toussaint, D. Laurenti, C. Mirodatos, C. Geantet, Co-processing of pyrolysis bio oils and gas oil for new generation of bio-fuels: Hydrodeoxygenation of guaiacol and SRGO mixed feed, Catal. Today 143 (2009) 172-178, https://doi. org/10.1016/j.cattod.2008.11.024.

[15] N. Bergvall, L. Sandstorm, F. Weiland, O.G.W. Ohrman, Corefining of fast pyrolysis bio-oil with vacuum residue and vacuum gas oil in a continuous slurry hydrocracking process, Energy Fuel 34 (2020) 8452-8465, https://doi.org/ 10.1021/acs.energyfuels.0c01322.

[16] N. Bergvall, R. Molinder, A.C. Johansson, L. Sandstrom, Continuous slurry hydrocracking of biobased fast pyrolysis oil, Energy Fuel 35 (2021) 2303-2312, https://doi.org/10.1021/acs.energyfuels.0c03866.

[17] C. Sepúlveda, N. Escalona, R. García, D. Laurenti, M. Vrinat, Hydrodeoxygenation and hydrodesulfurization co-processing over ReS2 supported catalysts, Catal. Today 195 (2012) 101-105, https://doi.org/10.1016/j.cattod.2012.05.047.

[18] E. Laurent, B. Delmon, Study of the hydrodeoxygenation of carbonyl, carboxylic and guaiacyl groups over sulfide CoMo/ $\gamma$-A1203 and NiMo/ $\gamma$-A1203 catalyst. II. Influence of water, ammonia and hydrogen sulfide, Appl. Catal. A: General 109 (1994) 97-115, https://doi.org/10.1016/0926-860X(94)85005-4. 
[19] A.R. Costa da Cruz, J.J. Verstraete, N. Charon, J.F. Joly, A Monte Carlo method for the simulating hydrotreating of bio-oil model compounds, Chem. Eng. J. 377 (2019), 120144, https://doi.org/10.1016/j.cej.2018.10.081.

[20] A. Dimitriadis, L.P. Chrysikou, G. Meletidis, G. Terzis, M. Auersvald, D. Kubička, S. Bezergianni, Bio-based refinery intermediate production via hydrodeoxygenation of fast pyrolysis bio-oil, Renew. Energy 168 (2021) 593-605, https://doi.org/10.1016/j.renene.2020.12.047.

[21] A. Dimitriadis, D. Liakos, U. Pfisterer, M. Moustaka-Gouni, D. Karonis, S. Bezergianni, Impact of hydrogenation on miscibility of fast pyrolysis bio-oil with refinery fractions towards bio-oil refinery integration, Biomass Bioenergy 151 (2021), 106171, https://doi.org/10.1016/j.biombioe.2021.106171.

[22] P. Manara, S. Bezergianni, U. Pfisterer, Study on phase behavior and properties of binary blends of bio-oil/fossil-based refinery intermediates: a step toward bio-oil refinery integration, Energy Convers. Manag. 165 (2018) 304-315, https://doi. org/10.1016/j.enconman.2018.01.023.

[23] S. Conrad, A. Apfelbacher, T. Schulzke, Fractionated condensation of pyrolysis vapours from ablative flash pyrolysis, in: Hamburg, Germany Proceedings of 22rd European Biomass Conference \& Exhibition, 2014, pp. 1127-1133, https://doi. org/10.5071/22ndEUBCE2014-3CV.2.8.

[24] T. Schulzke, S. Conrad, J. Westermeyer, Fractionation of flash pyrolysis condensates by staged condensation, Biomass Bioenergy 95 (2016) 287-295, https://doi.org/10.1016/j.biombioe.2016.05.022.
[25] M. Auersvald, B. Shumeiko, M. Staš, D. Kubička, J. Chudoba, P. Šimáček, Quantitative Study of Straw Bio-oil Hydrodeoxygenation over a Sulfided NiMo Catalyst, ACS Sustain. Chem. Eng. 7 (2019) 7080-7093, https://doi.org/10.1021/ acssuschemeng.8b06860.

[26] S. Bezergianni, A. Dimitriadis, Temperature effect on co-hydroprocessing of heavy gas oil-waste cooking oil mixtures for hybrid diesel production, Fuel 103 (2013) 579-584, https://doi.org/10.1016/j.fuel.2012.08.006.

[27] A. Dimitriadis, S. Bezergianni, Co-hydroprocessing gas-oil with residual lipids: effect of residence time and $\mathrm{H}_{2}$ /oil ratio, J. Clean. Prod. 131 (2016) 321-326, https://doi.org/10.1016/j.jclepro.2016.05.027.

[28] Z. Si, X. Zhang, C. Wang, L. Ma, R. Dong, An overview on catalytic hydrodeoxygenation of pyrolysis oil and its model compounds, Catalysts 7 (2017) 169, https://doi.org/10.3390/catal7060169.

[29] S.S. Schmitt, K. Raffelt, A. Zimina, B. Krause, T. Otto, M. Rapp, J. Grunwaldt, N. Dahmen, Hydrotreatment of fast pyrolysis bio-oil fractions over nickel-based catalyst, Top. Catal. 61 (2018) 1769-1782, https://doi.org/10.1007/s11244-0181009-z.

[30] S. Bezergianni, A. Dimitriadis, Comparison between different types of renewable diesel, Renew. Sust. Energ. Rev. 21 (2013) 110-116, https://doi.org/10.1016/j. rser.2012.12.042.

[31] J. Horáček, D. Kubička, Bio-oil hydrotreating over conventional CoMo \& NiMo catalysts: the role of reaction conditions and additives, Fuel 198 (2017) 49-57, https://doi.org/10.1016/j.fuel.2016.10.003. 